\title{
La venta de cargos municipales: tres casos concretos en Tarifa a principios del siglo XVIII
}

\author{
ANDRÉS SARRIÁ MUÑOZ
}

A la hora de analizar un tema tan propio del gobierno municipal en el Antiguo Régimen como el que aquí abordamos, cabe plantearse una cuestión inicial que nos acerque al centro del problema: ¿Cómo es posible que mientras la evolución general de las monarquías modernas en Europa tendía hacia una cada vez mayor centralización politica, se adoptara una práctica que venía a socavar esos mismos principios de la autoridad real? Pues, sin duda, la enajenación de la Corona de los oficios municipales, especialmente los de regidores, conllevaba una peligrosa carga de independencia política personal del poseedor con respecto al Estado. Se trata de dos ideas exactamente divergentes en su concepción de la administración pública. Sin embargo, fueron de la mano durante todo el período que comprende la Edad Moderna, constituyendo éste uno de los aspectos de más interesante estudio sobre la Administración pública. En definitiva, la venta de oficios públicos en el municipio castellano tuvo una larga y ambigua existencia. Su partida de nacimiento se sitúa en la baja Edad Media, desapareciendo en los albores de la contemporaneidad española, esto es, con las cortes de Cádiz y su labor desmanteladora de los restos feudovasalláticos que aún pervivían en la estructura social y política del país ${ }^{1}$.

No vamos a entrar aquí en el análisis detallado de la política regia en este aspecto; señalemos sólo que los reyes castellanos se debatieron siempre entre un deseo por erradicar la enajenación de los oficios públi-

\footnotetext{
- Para una visión rápida y esclarecedora del desarrollo de la venalidad de los oficios en Castilla véase Dominguez Ontzz, A., "La venta de cargos y oficios públicos en Castilla y sus consecuencias económicas y sociales", en Instituciones y sociedad en la España de los Austrias. Barcelona, Ariel 1985, págs. 146-183.
} 
cos y la realidad de verse obligados a acudir reiteradamente a esta práctica. Lógicamente, la razón está en que constituía una recurrente y limpia fuente de ingresos para la frágil Hacienda real, siempre embarcada en gastos muy superiores a sus propias posibilidades.

El siglo xvIII comenzó para España con un cambio de dinastía. A la nueva casa reinante se le atribuye la pretensión de querer llevar a cabo reformas estructurales en la chirriante maquinaria administrativa de los últimos Austrias. Sin duda, la venalidad de los cargos públicos municipales representaba uno de los aspectos más negativos de la herencia dejada por Carlos 11 y sus antecesores. Sin embargo, Felipe V no tuvo más remedio que continuar con esa venta de cargos, a pesar de sus propósitos reformadores del aparato administrativo español. Las necesidades económicas originadas por la guerra de Sucesión y otros posteriores conflictos bélicos, le obligaron a echar mano de esta segura fuente de ingresos, pues evidentemente, las exigencias de la Hacienda se agudizaban en aquellos momentos de mayores dificultades para la monarquía.

Los cargos y oficios concejiles eran muy variados, dependiendo, lógicamente, de las necesidades del municipio en cuestión. Si se trata de una ciudad relativamente grande, como puede ser el caso de Málaga, el número de esos funcionarios era bastante elevado, según podemos observar en los estudios que Quintana Toret y M. ${ }^{a}$ Carmen Mairal han realizado sobre Málaga en la segunda mitad del xvil y de $\mathrm{M}^{\text {a }}$ Carmen Mairal para el reinado de Carlos $11 \mathrm{I}^{2}$. Por nuestra parte, y en un intento de delimitar el campo y objeto concreto de este artículo, nos permitimos echar mano de la reconocida autoridad de Francisco Tomás y Valiente, quien hace una clasificación de los oficios enajenables en tres tipos: a) los «oficios de pluma»: escribanos y notarios; b) los "oficios de poder»: regidores, alguaciles mayores, alféreces mayores, etc.; y c) "oficios de dineros": término en que engloba muy diversos cargos relacionados con la Hacienda real, aunque normalmente dentro del ámbito municipal, tales como contadores, tesoreros, ciepositarios, etc. ${ }^{3}$.

En otro lugar hacemos un breve estudio del gobierno municipal tarifeño a comienzos del siglo xvII4 ${ }^{4}$, y no tenemos constancia de que se ven-

\footnotetext{
2 Quintana Toret, F. J., "La organización del Consejo malagueño bajo Carlos Il (16651700)" Jábega, n. 46. Málaga 1984, págs. 35-40; Mairnl Jimenez, M. Carmen, Cargos y oficios públicos en la Málaga de Carlos III. Servicio de Publicaciones de la Diputación Provincial de Málaga, 1990.

'TOMÁs y Valiente, F., Gobierno e instituciones en la España del Antiguo Régimen, Madrid, Alianza Universidad, 1982, pág. 161.

"Sarria Muñoz, A., "Gobierno municipal en Tarifa a comienzos del siglo xvill, Almoraima, Revista de Estudios Campogibraltareños, n. 5 de abril de 1991, págs. 197-208.
} 
La venta de cargos municipales: tres casos concretos en Tarifa a...

diera alguno de los últimos cargos señalados, sino que eran adjudicados periódicamente por el cabildo. Vamos, pues a tratar aqui sobre algunos aspectos de la forma de acceso a sus cargos de los distintos componentes del cabildo propiamente dicho: regidores, jurados y escribanos. Por lo que respecta al cargo de corregider, como sabemos, en la Corona castellana nunca fue objeto de compraventa. Analizaremos documentos de cada uno de los citados oficiales del concejo, sin más pretensión que la de ser tres casos entre los cientos y cientos de expedientes que existen en los municipios castellanos de la Edad Moderna. Para el regidor y escribano se trata de sus correspondientes titulos reales de confirmación; y de una escritura privada de compraventa en el caso del jurado.

\section{A) REGIDORES}

Para acceder al cargo de regidor del cabildo tarifeño los aspirantes debian reunir una serie de requisitos. Uno de ellos era el de pertenecer al estamento nobiliario. En el caso de una ciudad pequeña como Tarifa, es lógico pensar que se trataba de una baja nobleza, pero tan celosa de su status como la más alta; hablamos naturalmente de los hidalgos. Tan emparentado estaba para los tarifeños el ejercicio del gobierno municipal con este estamento, que al reclamar el título de hidalguía, un vecino pone como prueba irrefutable de su estado el que un familiar suyo habia sido caballero regidor, «lo cual ha sido y es acto distintivo por sólo permitirse a los hidalgos notorios ${ }^{5}$.

Así pues, el título no era otorgado sin previamente haber pasado por los formalismos establecidos legalmente. En este sentido, la Cámara de Castilla pedía información al Ayuntamiento acerca de si el solicitante cumplia las condiciones requeridas y no tener determinadas incompatibilidades. Así, por ejemplo, en diciembre de 1712 se recibió en Tarifa una carta notificando que por parte de Juan Moriano se habían presentado los papeles pretendiendo que se le despachase título de regidor, por renuncia de su padre. Pero para poder otorgárselo debia reunirse el cabildo e informar sobre si Juan Moriano era sujeto de buena vida y costumbres; si concurrian en él la suficiencia y capacidad requeridas; si contaba con algún hijo suyo ejerciendo el oficio de regidor. Por otra parte, no debía poseer tienda ni otro negocio en la ciudad ni ser parte interesada en los

${ }^{5}$ Archivo Municipal de Tarifa (AMT), Actas Capitulares, vol. n. ${ }^{\circ}$ 16, fols. 366-367. 
abastos públicos. Y reunidos los capitulares para tratar el asunto, contestaron que dicho Juan Moriano cumplia todos los requisitos exigidos, por lo que tenían por justa su pretensión ${ }^{6}$.

Es cierto que a veces podian poner ciertas objeciones, como asi 10 hicieron en 1720 al informar sobre Domingo Serrano. Éste también cumplía todas las condiciones señaladas anteriormente, pero le encontraban un serio inconveniente para poder entrar a ejercer el oficio de regidor en lugar de su padre. No era otro que el de ser soltero, «y no conocérsele caudal alguno, estando debajo de la patria potestad a expensas de su madre». Sobre todo, este último detalle no dejaba de tener su importancia, ya que el oficio estaba gravado con tributos correspondientes a ciertos censos. Por tanto, era lógico que los capitulares se preocuparan por la insolvencia económica del posible nuevo regidor "cuyas circunstancias pone esta ciudad en la alta consideración de su Majestad, para que enterado de ellas, se digne resolver lo que fuere de su Real agrado»?. Pero, a pesar de todo, Domingo Serrano tomaría posesión sin ningún problema en el cabildo de 1 de noviembre de $1720^{\circ}$.

Por lo que se refiere a las cantidades manejadas en la compraventa, sabemos que el título de regidor costaba en Tarifa 5.000 reales a comienzos del siglo xVIII, salvo si se trataba de regidor de preeminencia, en cuyo caso alcanzaba los 9.000 reales, según veremos más adelante. Si tenemos en cuenta que en sí mismo el cargo no suponía más que una modestísima suma en concepto de salario, no hacen falta muchas aclaraciones jara entrever los posibles beneficios que el propietario percibiría por otras muy distintas vías. El poder político que conellevaba resulta algo evidente; el prestigio social era de la mayor importancia, también; y los intereses económicos estaban presentes en todas sus actuaciones. Un ejemplo de esto último lo tenemos en el ejercicio de las diputaciones que anualmente correspondían a cada regidor, a través de las cuales los capitulares controlaban la vida económica de la ciudad ${ }^{9}$.

Hemos recogido en las actas del cabildo tarifeño varios casos en los que se dan las diferentes formas de acceso al cargo; éstas son: por herencia, renuncia o compra. En principio, la monarquia no percibia ningún dinero por la transferencia privada del cargo, al tratarse de una formalidad totalmente gratuita. Pero, como ya hemos comentado, debido a las

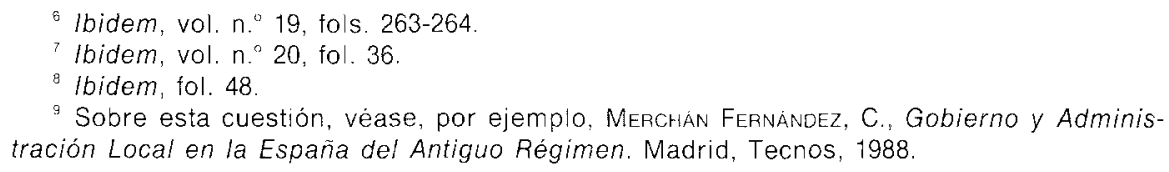


dificultades que tan repetidamente atravesaría la Hacienda castellana, ésta se vio en la necesidad de incluir entre sus fuentes de ingresos el producto correspondiente a estas transmisiones. En virtud de ello, el adquiriente debía pagar a la Corona la «media annata», es decir, en teoria la mitad de los ingresos obtenidos durante el primer año en el disfrute del cargo. Sin embargo, como esta cuantía era muy difícil de determinar, la Real Hacienda cobraba una cantidad fijada de antemano, y que Tomás y Valiente ha establecido en el 2,5 por 100 del valor del oficio en cuestión ${ }^{10}$.

Ahora vamos a analizar un caso concreto de transmisión de regiduria; se trata del título de regidor de Diego de Morales y Ribera, dado en Barcelona el 10 de diciembre de $1701^{11}$. La cédula comienza haciendo un breve historial de los antecedentes del oficio y de las transmisiones privadas que ha habido; es decir, de como ha llegado a la persona a la que ahora se le expide el título. Señala que al haber fallecido sin heredero directo, _ «línea que sucediese»-, su último poseedor, Rafael de Morales y Paz, se procedió a cumplir con las cláusulas dispuestas por los fundadores del mayorazgo. La primera consistía en fundar dos capellanias a costear con los bienes de dicho mayorazgo.

Posteriormente, se precedió a sacar al pregón esos bienes, y entre ellos el oficio de regidor. De las diferentes pujas que hubo, se remató en el licenciado Luis de Morales, clérigo presbitero, en precio de 9.000 reales de vellón. Sin embargo, esta cantidad no debía hacerla efectiva al contado, sino que quedaba como censo impuesto sobre dicho oficio «al redimir y quitar, a pagar de rédito cada año a dichas capellanías» 450 reales de vellón. Todo ello según escritura pública de venta otorgada por los capellanes el 10 de mayo de 1701. Otra condición impuesta era la de no ejercer al mismo tiempo otro cargo de regidor ni juraduría, aunque en realidad ésta debería ser un requisito previo a la concesión del título, según hemos comentado.

Por todo ello, parece que no fue más que una operación premeditada, pues unos meses más tarde el clérigo Luis de Morales renunció el oficio en su hermano Diego, capitán del ejército, por otra escritura de 16 de noviembre del mismo año. En consecuencia, el rey renovaba el nombramiento, dando ahora título de regidor al mencionado Diego de Morales:

\footnotetext{
10 Tomás y Valiente, F., Op. cit, pág. 171.

$"$ AMT, Actas Capitulares, vol. n."16, fols. 84-87. Copia del título de regidor de preeminencia de Diego de Morales y Ribera.
} 
«Y yo lo he tenido por bien y es mi voluntad que vos, el dicho don Diego de Morales y Ribera, seáis ahora y de aquí adelante mi regidor de Tarifa, en lugar del dicho don Rafael de Morales y Paz".

Nótese cómo su hermano, de quien realmente tomaba el cargo, no aparece aquí. Lógicamente, el nuevo titular también quedaba obligado a efectuar el pago del censo de 450 reales impuesto a favor de las dos capellanias fundadas.

En el título también se contemplaba la posibilidad de que los herederos fuesen un menor de edad o una mujer, sobreentendiéndose que éstos no podrian ejercer el oficio. En ese caso se les daba facultad para nombrar persona que lo pudiera ejercer mientras llegaba a la mayoría de edad, si era varón, o la hija o mujer contraía matrimonio. En este último supuesto ésta llevaría como dote, precisamente, el oficio de regidor, que de esta forma pasaría a la titularidad del marido, y, en consecuencia, quedaba vinculado al mayorazgo del nuevo propietario. Y concreta aún más: «aunque sea en perjuicio de las legítimas de los otros vuestros hijos».

El rey mandaba al concejo y autoridades en general de Tarifa que recibiesen al nuevo regidor juntándose a cabildo, para llevar a cabo el juramento y la toma de posesión como tal regidor. $Y$, asimismo, ordenaba que una vez cumplido con este formalismo:

«os guarden y hagan guardar todas las honras, mercedes, gracias, franquicias, libertades, exenciones, preheminencias, prerrogativas e inmunidades y todas las otras cosas que por razón del dicho oficio os tocaren y pertenecieren".

Pero además de éstos, Diego de Morales tenía otros privilegios que le venian de su condición de regidor llamado de preeminencia. En virtud de ello, se le reconocia antigüedad y precedencia sobre todos los demás regidores, excepto el alférez mayor y alguacil mayor. Y se equiparaba con estos dos oficiales en que tendría el mismo derecho que ellos en cuanto a poder entrar con armas en el ayuntamiento. Otra perrogativa que se le concedia era la de poder nombrar a un teniente para servir el oficio en sus ausencias, gozando éste de los mismos derechos que el titular.

La propiedad sobre el oficio le era otorgada "por juro de heredad perpetuamente para siempre jamás", y esto se entendia tanto para Diego de Morales como para sus herederos y sucesores. Asimismo, quedaban recogidas las posibles formas de traspaso de titularidad del oficio, que como una propiedad que formaba parte de sus bienes, lo podria ceder, renunciar, traspasar y disponer de él en vida o en muerte, por testamento o en cualquier otra manera. Por otra parte, se apunta que Diego de Mo- 
rales no podria ser privado de su oficio por ninguna razón, excepto cuando cometiere los delitos de lesa majestad, herejía o sodomía.

Por último, se reconocía que todo lo dispuesto en este título quedaba a salvo de cualquier ordenamiento legal en contra; dictaminando:

"que se guarde y cumpla todo lo contenido en esta mi carta, sin embargo, de cualesquier leyes y pragmáticas destos mis reinos y señoríos, estilo, uso y costumbre y otra cualquier cosa que pueda haber en contrario".

En definitiva, los regidores compraban su oficios, adquiriendo con ello la plena propiedad sobre el mismo, con lo cual la patrimonialización de estos cargos públicos en los municipios castellanos habia triunfado ${ }^{12}$.

\section{B) JURADOS}

Son muy escasas las alusiones que existen en las actas del cabildo tarifeño del siglo xvIII sobre la labor desarrollada por los jurados. $Y$, curiosamente, la mayor parte de esas referencias están relacionadas con alguna disputa entre los jurados y los regidores. En general, los jurados tenian un papel ciertamente poco relevante en el gobierno de las ciudades, y sobre todo en las pequeñas, donde los regidores ejercían un absoluto dominio sobre ellos. Sin duda, el hecho de que en estas pequeñas poblaciones el número de jurados fuera muy corto, aumentó esa indefensión con respecto al grupo de los regidores. Concretamente, en la Tarifa de comienzos del siglo Xvill sólo hubo un jurado, aunque posteriormente se le uniría otro más. Y podemos asegurar que sólo cuando fueron dos, su labor en el cabildo empezó a hacerse notar, aunque solamente fuese para defender intereses propios frente a los de los regidores ${ }^{13}$.

Que los cargos públicos municipales formaban parte de los bienes patrimoniales de su poseedor, podemos comprobarlo en el oficio de jurado, tanto o más claramente si cabe que en el caso de los regidores. Para saber en qué condiciones se podían hacer transmisiones de esta clase, abordamos ahora el análisis de la escritura de compravente del oficio de

\footnotetext{
12 Cfr. Tomas y VAliente, F., "Las ventas de oficios de regidores y la formación de oligarquias urbanas en Castilla (siglos XVII-XVIII), en Historia. Instituciones y Documentos, n. ${ }^{\circ} 2$. Sevilla 1975, págs. 525-545.

${ }^{13}$ Cfr. Sarria Muñoz, A., Op. cit.
} 
jurado efectuada entre Tomás Moreno y Pedro Lozano del Río ${ }^{14}$. Tomás Moreno, el jurado que habia en 1699, se vio forzado a vender su oficio en razón de su penosa situación económica, según declaración en la que justifica tal decisión. Así, sabemos que tras la muerte de su mujer, Luciana Moreno y Mesa, se encontraba con muchos hijos y obligaciones, sin otros bienes muebles ni raices con que poder mantenerlos, pues los que tenia en vida de su mujer los habian gastado debido a los apuros originados por las adversas condiciones climáticas de aquellos años, que dieron lugar a muy malas cosechas y las consiguientes carestias de pan y otros productos alimenticios. Por tanto, ahora acudía a la enajenación de su cargo en el cabildo como último recurso, después de haber perdido todo lo demás.

Para poder realizar la venta, habia de probar que efectivamente se hallaba en la necesidad de echar mano de esta propiedad, para lo cual se dirigió al corregidor en estos términos:

"A Vm. pido y suplico mande recibirme información sumaria de cómo, a causa de las dichas necesidades que padecemos, para remediarlas en la parte que pudiere, me es útil y provechoso a mi y a los dichos mis hijos menores el vender el dicho oficio de jurado".

Y dado que exponia como razón principal para realizar dicha venta la de alimentar a sus hijos pequeños, el primer paso que debió dar fue recabar el visto bueno del "padre general de menores". El 13 de mayo de 1699 el corregidor dictó auto para que éste último acudiese ante el escribano comisionado para la compraventa y recibiese la información al respecto del propio Tomás Moreno; «en vista de lo cual, se proveeria lo que lugar hubiese». Y, en efecto, Baltasar de Arcos Moriano, regidor y "padre general de menores", dio su testimonio sobre la veracidad de la adversa situación económica por la que atravesaba y las ineludibles necesidades que le obligaban a llevar a cabo la venta.

Por otra parte, Tomás Moreno hubo de presentar a tres testigos que, mediante sus declaraciones ante notario, confirmaran la extrema falta en que se encontraba. Lógicamente, todos ellos aseguraron que eran ciertas las razones expuestas por Tomás Moreno para solicitar la licencia de venta, viniendo a coincidir en que:

\footnotetext{
${ }^{14}$ Archivo de Protocolos Notariales de Algeciras. Sección Tarifa, Antonio Chico Alemán, años 1700-1705, fols. 29-33. Venta del oficio de jurado a Pedro Lozano.
} 
«tiene por cierto el testigo que es de útil y conveniencia el vender el dicho oficio de jurado, para con su valor dar remedio a los dichos sus hijos; y esto es público y notorio".

Finalmente, el día 15 de mayo, el corregidor, en vista de todos estos testimonios, dio permiso a Tomás Moreno para poder vender en «almoneda o fuera de ella el dicho oficio de jurado a la persona que por bien tuviere". Y tres dias más tarde, otorgaba carta de venta ante notario y los testigos de rigor. El precio se estipuló en 1.650 reales de vellón; pero, además, sobre este oficio también había impuesto un censo de dos ducados y medio, que anualmente se pagaban a Pablo de Villalba, vicario y beneficiado de las iglesias de la ciudad. En señal de posesión, y hasta que el adquirente, Pedro Lozano, recibiera el título del rey, Tomás Moreno le entregaba el suyo.

Pero con esto, la operación quedaba concluida sólo en parte, pues ya sabemos que formalmente los cargos municipales requerian el nombramiento real para que tuviesen efecto. Por tanto, Pedro Lozano no podía tomar posesión del suyo en el cabildo tarifeño hasta que no recibiera su título de tal jurado. Lo presentó, finalmente, en el cabildo de 31 de diciembre de 1700 , en el cual se le dio posesión de su cargo, según testimonio recogido en el acta correspondiente a ese día:

«En este cábildo se presentó por mí, el escribano, un real título de Su Majestad, firmado del rey nuestro señor, don Carlos Segundo, que goza de Dios, despachado por la Real Cámara de Castilla, su data en Madrid, a trece de octubre de mil setecientos, refrendado del señor don Francisco Nicolás de Castro Gallego, secretario de Su Majestad, por el cual hace merced a Pedro Lozano del Río de un oficio de jurado perpetuo, por juro de heredad, de esta ciudad, en lugar de Tomás Moreno Cordero, que lo ejercia, renunció y vendió al susodicho con las cláusulas de perpetuidad concedidas a sus autores" ${ }^{15}$.

\section{C) ESCRIBANOS}

Por último, vamos a referirnos al colectivo socioprofesional de los escribanos, de gran transcendencia en cualquier ciudad, como muy bien han

\footnotetext{
${ }^{15}$ AMT, Actas Capitulares, vol. n. ${ }^{\circ} 16$, fols. 64-65.
} 
interpretado Marion Reder en el caso de Málaga ${ }^{16} \mathrm{y}$, más recientemente, David González Cruz, para Huelva ${ }^{17}$. Aqui sólo analizaremos el cargo de escribano del concejo, del cual ya sabemos que aunque no era propiamente un miembro del cabildo, resultaba un funcionario imprescindible en él. Sus funciones consistían en recoger los acuerdos capitulares en los libros de actas correspondientes, dándoles la legalidad juridica requerida. En el título de escribano de cabildo otorgado a Manuel de Montañara, en Madrid, con fecha de 1 de agosto de $1707^{18}$, también se hace un breve historial de los propietarios.

En este caso concreto se nos informa de que Carlos II, por despacho de 14 de mayo de 1691, concedió a Francisco de Quintanilla el oficio de escribano de número y concejo de Tarifa, en lugar de Juan de Arcos Robles. Francisco de Quintanilla se habia casado con doña Sebastiana de Quintanilla, a quien habia dejado poder para testar. Tras quedar viuda, doña Sebastiana pidió que se apreciase el oficio de escribano que dejó su marido y se le adjudicase su propiedad como parte de pago de lo que le correspondiese por su dote y demás derechos; todo ello como requisito previo a la proyectada venta.

Una vez cumplimentada la información y diligencias formales, el corregidor, don Juan Bautista de Bereceibar, por auto de 28 de mayo de 1707, adjudicó dicho oficio a doña Sebastiana de Quintanilla, quien, por tanto, quedaba como nueva y plena propietaria, con total libertad para disponer de él como quisiera. El oficio en cuestión fue apreciado en 3.000 reales de vellón, de cuyo valor se habia de descontar los censos impuestos sobre él.

En consecuencia, y usando de su derecho, la poseedora otorgó escritura de venta ante Gabriel de Quintanilla, a favor de Manuel de Montañara, por el referido importe de 3.000 reales de vellón. Sin embargo, esta cantidad estaba hipotecada en su práctica totalidad, pues el comprador sólo debió pagar al contado 250 reales; con los restantes 2.750 reales habian de costearse dos censos impuestos a favor de sendas capellanías: uno de diez ducados de rédito y el otro de dos y medio anuales.

Reunidos todos los informes requeridos, tales como testimonios, escritura de venta, y demás papeles, se presentaron éstos ante el Consejo

\footnotetext{
16 Reder Gadow, M., «Breve estudio sobre los escribanos públicos malagueños a comienzos del siglo Xvill, Baetica, 1982, págs. 195-204

"Gonzalez Cruz. D. Escribanos y notarios en Huelva durante el Antiguo Régimen (17011800). Huelva, Univ. de Sevilla, 1991.

${ }_{18}$ AMT, Actas Capitulares, vol. n." 17, fols. 190-192. Copia del título de escribano del cabildo y público otorgado a Manuel de Montañara.
} 
de la Cámara, órgano que expedia estos títulos en nombre del rey, según ya hemos comentado. Formalmente, el monarca podia rehusar el rombramiento aunque esto no era normal. No obstante, y en cualquier caso, el adquiriente debía demostrar su capacidad para el oficio, previo examen ante un tribunal de Sevilla, tras lo cual el rey concedia, efectivamente, dicho título, mediante la fórmula conocida:

"Mi voluntad es que ahora y de aquí adelante, vos, el dicho Manuel de Montañara, seáis mi escribano del número y Concejo de la dicha Tarija, en lugar del dicho Francisco de Quintanilla».

En el título se especifica el área de actuación que abarcaba su oficio, ciertamente muy amplio al ser al mismo tiempo notario público y escribano del cabildo municipal. Concretamente, comprendian éstas: «todas las escrituras, contratos, poderes, ventas, censos, testamentos, cobdicilios, compromisos, obligaciones y los hechos del Concejo y otras cualesquiera escrituras y autos judiciales y extrajudiciales que ante vos pasaren y otorgaren en la dicha Tarifa y su jurisdicción».

Se le otorgaba el oficio «por juro de heredad, perpetuamente, para siempre jamás»; y, por tanto, sus herederos tenían derecho a traspasarlo por venta o cualquier otra operación, como bienes suyos propios. Y de la misma forma que ocurría con el de regidor, en el caso de que el nuevo poseedor del título de escribano fuese un menor de edad o mujer, podría nombrar a una persona que lo administrase hasta la mayoría de edad, o se casaba, si se trataba de una mujer. Incluso se señala que si el actual propietario moría sin haber manifestado claramente en su testamento a quién debía corresponder el oficio, éste iría a parar a quien más derecho tuviere para heredar sus bienes. Y si fuese el caso que hubiere varios herederos, deberian llegar a un acuerdo para adjudicárselo a uno de ellos.

Igualmente, se declara que Manuel de Montañara había efectuado el preceptivo pago de la «media annata» por el derecho de perpetuidad de dicho oficio. El valor de ésta llegó riasta los 3.400 maravedies, es decir, 100 reales de vellón, de los que doña Sebastiana habría de abonar 1.700 maravedies, y los 1.700 restantes al adquiriente. Dichos 100 reales corresponden al $3,33 \%$ del precio del oficio, lo cual eleva en una pequeña cantidad del porcentaje de $2,5 \%$ que señala Tomás y Valiente para estas transmisiones. Esta tasa habria de ser abonada por cada uno de los sucesores en el cargo, con lo cual quedaban automáticamente renovados sus derechos de perpetuidad. Señalemos también, por último, que el propietario no podría ser despojado de su título por ningún motivo ni razón, salvo cuando incurriese en los consabidos delitos de herejia, lesa majestad o sodomia. 